\title{
Effects of Scan Strategy on Thermal Properties and Temperature Field in Selective Laser Melting
}

\author{
Elham Mirkoohi ${ }^{1 *}$, Daniel E. Sievers ${ }^{2}$, Hamid Garmestani ${ }^{3}$, and Steven Y. Liang ${ }^{1}$ \\ ${ }^{1}$ Woodruff School of Mechanical Engineering, Georgia Institute of Technology, Atlanta, GA 30332, USA; \\ elham.mirkoohi@gatech.edu \\ 2 Boeing Research and Technology, Ceramics, Extreme Environments \& Metals, Huntsville, Al, 35824, USA \\ ${ }^{3}$ School of Materials Science and Engineering, Georgia Institute of Technology, Atlanta, GA 30332, USA
}

\begin{abstract}
Temperature field is an essential attribute of metal additive manufacturing in view of its bearings on the prediction, control, and optimization of residual stress, part distortion, fatigue, balling effect, etc. This work provides an analytical physics-based approach to investigate the effect of scan strategy parameters including time delay between two irradiations and hatching space on thermal material properties and melt pool geometry. This approach is performed through the analysis of the distribution of material properties and temperature profile in three-dimensional space. The moving point heat source approach is used to predict the temperature field. To predict the temperature field during the additive manufacturing process some important phenomena are considered. 1) Due to the high magnitude of temperature in the presence of the laser, the temperature gradient is usually high which has a crucial influence on thermal material properties. Consequently, the thermal material properties of stainless steel grade 316L are considered to be temperature-dependent. 2) Due to the repeated heating and cooling, part usually undergoes several melting and solidification cycles. This physical phenomenon is considered by modifying the heat capacity using the latent heat of melting. 3) The multi-layer aspect of metal AM process is considered by incorporating the temperature history from the previous layer since the interaction of the successive layers has an impact on heat transfer mechanisms. 4) Effect of heat affected zone on thermal material properties is considered by the superposition of material properties in regions where the temperature fields of two consecutive irradiations have an overlap since the consecutive irradiations change the behavior of the material properties.

The goals are to 1) investigate the effects of temperature-sensitive material properties and constant material properties on the temperature field. 2) Study the behavior of thermal material properties under different scan strategies. 3) Study the importance of considering the effect of heat affected zone on thermal material through the prediction of melt pool geometry. 4) Investigate the effect of hatching space on melt pool geometry.

This work is purely employed physics-based analytical models to predict the behavior of material properties and temperature field under different process conditions, and no finite element modeling is used.
\end{abstract}

Keywords: Selective Laser Melting; Temperature Modeling; Melt Pool Geometry; Hatching Space; Time delay

\section{Introduction}


Selective laser melting (SLM) is rapidly developing and gaining attention in the industry to manufacture parts and assemblies with a variety of material systems for many different applications. Compared to conventional manufacturing methods such as machining, grinding, milling, etc. layer by layer deposition of material substantially reduces the direct material cost per part due to the scrap rate reduction. Moreover, Zhang [1] indicates that the SLM processes provide near net shape and intricate shapes with a good surface finish which reduces postprocessing procedures. AM also enables single step, net shape processing of complex parts. On the other hand, due to the existence of high-temperature gradient, the products experience residual stress, part distortion, and failure. To reduce the probability of occurrence of the aforementioned problems in additive manufacturing (AM) processes, numerical analysis based on finite element method (FEM), analytical models, and also experimental procedures are used to analyze the temperature distribution in metal AM. An accurate prediction of temperature distribution could help to minimize the above-mentioned difficulties through the optimization of the process. The final performance of the additively manufactured part highly depends on the process parameters such as scan speed, laser power, hatching space, layer thickness, etc.

The finite element models are developed to investigate the temperature distribution and melt pool geometry in AM processes. Mukherji et al. used FEM to predict the temperature in laserassisted AM. Mukherjee et al. [2] used the three-dimensional transient heat transfer and fluid flow to calculate the temperature field. They have mentioned that prediction of temperature field in AM has a substantial influence on residual stress and distortion prediction. Cheng et al. [3] developed a 3D thermal model using FEM to predict the temperature in electron beam additive manufacturing (EBAM) processing. The predicted melt pool geometry is compared to experimental results. The average error obtained between the predicted melt pool and experimental values is around 32\%. Lee and Farson [4] conducted an FE simulation to simulate multilayer single-track laser additive manufacturing powder deposition of IN718. In this work, they have been able to predict the melt pool peak temperature and deposit geometry. Michaleris [5] used a quite element method and an inactive element method to predict the temperature profile in metal AM. They have concluded that the inactive element method reduces the number of degrees of freedom at the initial stage, but it substantially decreases the computational efficiency compared to the quite element method. Mirkoohi et al. [6] proposed a two-dimensional analytical model to predict the surface temperature and melt pool geometry by considering the effects of temperature-dependent material properties, liquid/solidification phase change, and also the effect of layer addition. In another work, they have introduced five different heat source models to predict the temperature field. They have shown that each heat source model can predict the temperature field accurately within a certain range of process parameters [7]. Ribeiro et al. [8] used an analytical model to predict the temperature field for a moving heat source. In this model, the boundary conditions are considered. Craeghs et al. [9] used a high-speed camera to monitor the melt pool geometry and also to detect the errors and material discontinuities in the powder bed system. Krauss et al. [10] used an Infrared (IR) camera to detect the pores and irregularities in laser PBF processing by the observation of temperature distribution. Price et al. [11] used an IR image to determine the repeatability of temperature measurements, molten pool emissivity, molten pool dimensions, build height effect on temperature profiles, transmission losses and overhanging structure thermal effects.

Finite element models are widely utilized in the sintering process modeling and its effectiveness is verified by obtaining close agreement with experimental values. However, it is challenged by 
the fact that FE simulations are computationally expensive and that most of the time causes the analysis of the whole process to be time untraceable [12]. Experimental measurements of peak temperature and melt pool geometry could provide knowledge about the effects of scanning strategy, such as laser power, scan speed, hatching space and time spacing on the melt pool geometry. However, running experiments for understanding all the physical aspects of AM processes are time consuming and expensive. On the other hand, the analytical models are hard to obtain but the computational efficiency is relatively high which makes the real-time monitoring of any manufacturing processes possible [13-15]. The temperature modeling could be done in less than a minute using analytical closed-form solutions compare to hours or days when using FEM or experiments. Thus, in this work, a physics-based analytical model is used to predict the temperature field and investigate the effect of scan strategy on the behavior of material properties and temperature field.

The large temperature gradient could result in high tensile residual stress, part distortion, and undesirable microstructure evolution, hence, prediction of temperature history during the SLM process is of great importance [16,17]. Different magnitudes of hatching space and time delay could alter the magnitude of the thermal material properties; hence, it changes the heat transfer mechanisms. As a result, the hatching space and time spacing have a profound effect on the temperature field.

In this work, the physics-based analytical model is used to predict the temperature field. No finite element model (FEM) is used in this work. The temperature field is predicted using a moving point heat source approach. To accurately predict the temperature field during SLM process, the multi-physics aspect of metal AM should be considered. In this work, the thermal material properties are considered to be temperature-dependent since the steep temperature gradient has a crucial impact on the magnitude of the properties such as specific heat and thermal conductivity. Moreover, SLM parts usually undergo several melting and solidification cycles. Thus, this phenomenon is considered by modifying the specific heat using the latent heat of fusion. Furthermore, the multilayer aspect of metal AM process is considered by incorporating the temperature history from previous layers since the interaction of successive layers have a substantial impact on heat transfer mechanisms. Last but not least, consecutive irradiations would result in a melt pool and a heat-affected zone. The heat-affected zone would alter the properties of the material. Thus, in the prediction of the temperature, the effect of heat affected zone on thermal material properties should be considered using the superposition of the properties in which the temperature fields have overlap.

The goals of this study are as follows; 1 ) investigate the effects of temperature-sensitive material properties and constant material properties on the temperature field. 2) Study the behavior of thermal material properties under different scan strategies. 3) Study the importance of considering the effect of heat affected zone on thermal material through the prediction of melt pool geometry. 4) Investigate the effect of hatching space on melt pool geometry. The proposed model is validated using the measured melt pool geometries from literature.

\section{Approach and Methodology}

An analytical method is proposed herein to predict the temperature field and melt pool geometry by considering the effect of the scan strategy of time delay and hatching space. A moving point heat source approach is employed to predict the temperature field by considering the effect of the 
heat-affected zone on thermal material properties. The three-dimensional view of the model is shown in Figure 1. The heat loss due to convection and radiation is not considered in this work.

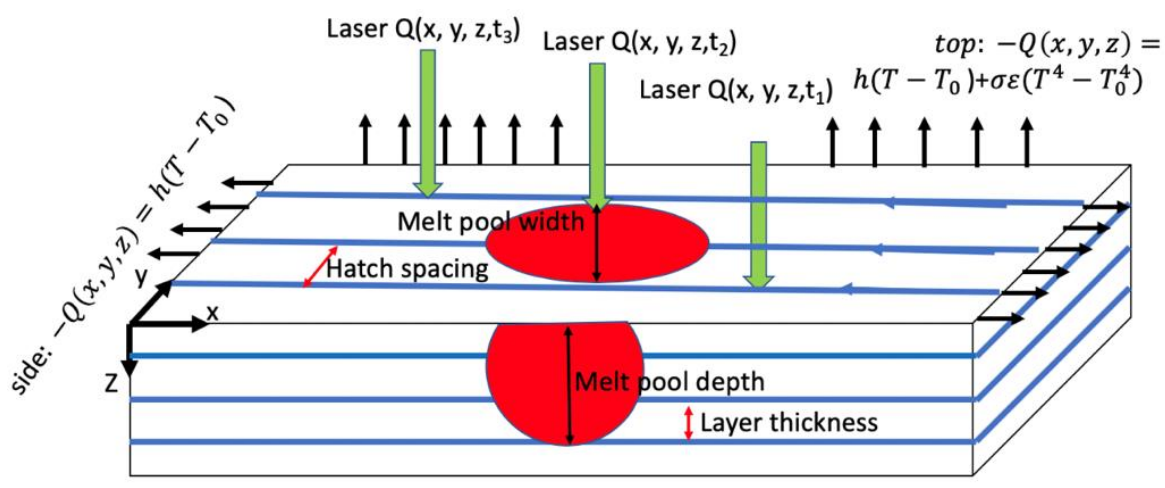

Figure 1. Illustration of the heat transfer mechanisms in metal additive manufacturing.

The temperature profile is obtained due to the heat input from the laser using point moving heat source approach. The general convection-diffusion formula is used to obtain the closed-form analytical solution of temperature as

$$
\rho c\left(\frac{\partial T}{\partial t}+v \frac{\partial T}{\partial x}\right)=\nabla(k \nabla T)+S
$$

where $\rho$ is material density, $\mathrm{c}$ is specific heat, $\mathrm{T}$ is the temperature, $\mathrm{t}$ is the time, $\mathrm{v}$ is the scan speed, $\mathrm{k}$ is thermal conductivity, and $\mathrm{S}$ is the heat sink.

Based on the steady-state condition the $\partial \mathrm{T} / \partial \mathrm{t}=0$ in equation (1), the equation would become

$$
\rho c(T)\left(v \frac{\partial T}{\partial x}\right)=\nabla(k \nabla T(T))+S
$$

where the thermal material properties are functions of temperature. Using the separation of variables, the closed form solution of temperature would be

$$
T=\frac{P \alpha}{4 \pi k R} \exp \frac{-v(R-x)}{2 D}+T_{0}
$$

where the thermal material properties are functions of temperature. Using the separation of variables, the closed-form solution of temperature would be

$$
R=\sqrt{x^{2}+y^{2}+z^{2}}
$$

$D$ is the thermal diffusivity which could be calculated as

$$
D=\frac{k(T)}{\rho C_{p}^{m}}
$$

Due to the steep temperature gradient during metal AM process, the thermal material properties such as thermal conductivity and specific heat vary significantly. Consequently, the material properties are considered to be temperature-dependent. Moreover, the build part undergoes several melting and solidification cycles due to the multi-layer and multi-track aspects of the AM processes. This physical phenomenon is considered by modifying heat capacity using latent heat of fusion 


$$
C_{p}^{m}=c_{p}(T)+L_{f} \frac{\partial f}{\partial T}
$$

In which $c_{p}(T)$ is temperature dependent specific heat, $L_{f}$ is latent heat of fusion, and $f_{l}$ is liquid fraction which can be calculated from

$$
f_{l}=\left\{\begin{array}{cc}
0, & T<T_{S} \\
\frac{T-T_{S}}{T_{L}-T_{S}}, & T_{S}<T<T_{L} \\
1, \quad T>T_{L}
\end{array}\right.
$$

where $T_{S}$ is solidus temperature and $T_{L}$ is liquidus temperature.

Since the interaction of successive layers have an essential impact on heat transfer mechanisms, the multi-layer aspect of metal AM process is considered by incorporating the temperature history from previous layers as explained in previous work [6].

Effect of heat affected zone on thermal material properties is considered. The heat-affected zone is the region where the temperature of the powder is less than melting temperature and more than the initial temperature. As shown in Figure 2, the first irradiation creates a melt pool and a heataffected zone. In the second irradiation, some regions of the powder are already affected by the first irradiation which causes the material properties to behave differently compared to the situation that the material is not affected by the laser previously. This effect is considered by the superposition of the material properties in regions of the temperature profile where the heataffected zone exists and has an overlap with the second temperature profile induced by the second

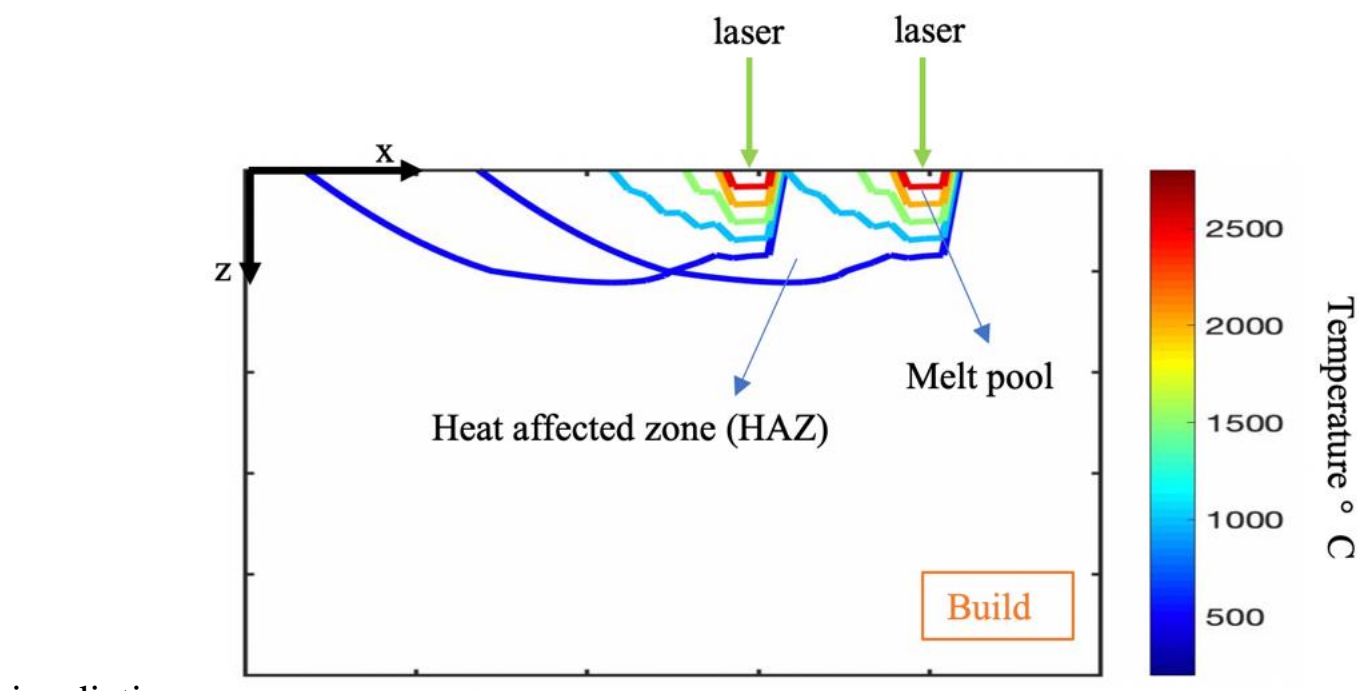

irradiation.

Figure 2. Illustration of the two consecutive irradiations and existence of heat affected zone.

For a given melting temperature, the melt pool width and depth can be calculated as

$$
N=\left\{n \mid n_{T}=T_{m}\right\}
$$




$$
\begin{gathered}
W_{\text {melt pool }}=\max \left|a_{y}-b_{y}\right|, \forall a \in N, b \in N \\
D_{\text {melt pool }}=\max \left|a_{z}-b_{z}\right|, \forall a \in N, b \in N
\end{gathered}
$$

where $\mathrm{n}$ represents the nodes in the medium, $n_{T}$ indicates the temperature at node $\mathrm{n}$, and $\mathrm{N}$ is a set of points where their temperatures are equal to melting temperature. $a$ and $b$ indicate all the points that belong to $\mathrm{N}$.

\section{Results and Discussion}

2.1. Effects of temperature-sensitive properties and constant properties on temperature field

In this section, the effects of temperature-sensitive and constant thermal material properties on temperature field are investigated, separately. The selected material is stainless-steel 316L. The laser power is $50 \mathrm{~W}$ and scan speed is $200 \mathrm{~mm} / \mathrm{s}$. The laser sits at $\mathrm{X}=0.5 \mathrm{~mm}, \mathrm{Y}=0.5 \mathrm{~mm}, \mathrm{Z}=0$ (surface). Figure 3 is a schematic of the top view of the build part which illustrates the laser location and study line. It should be noted that the absorptivity is 0.8 and the scan strategy is unidirectional.

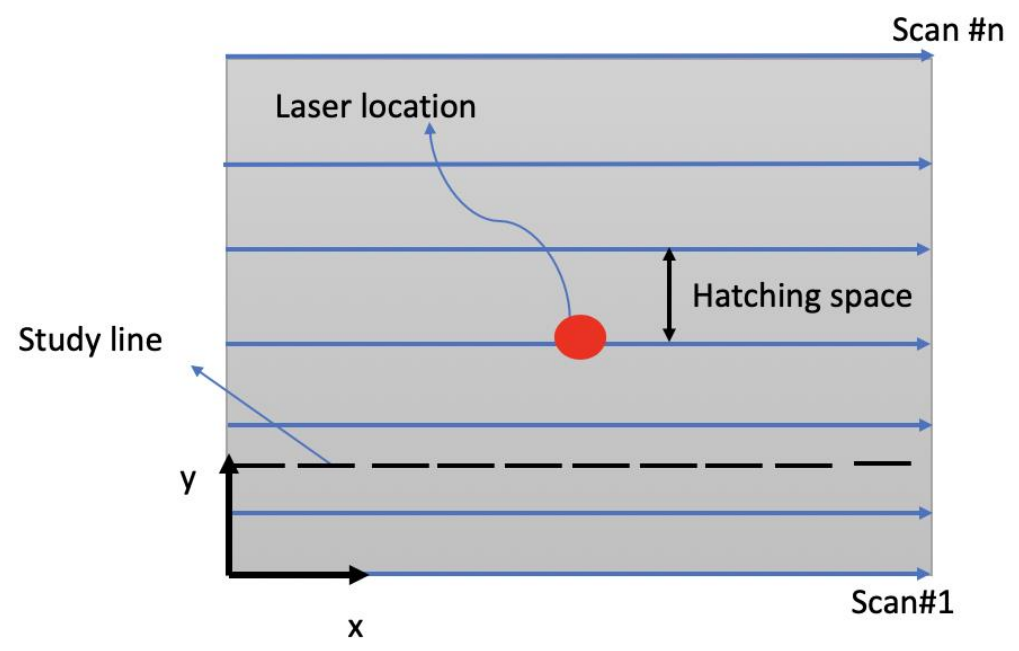

Figure 3. Top view of the build part illustrating the laser location and study line.

Figure 4 shows the predicted temperature distribution with constant thermal material properties. As illustrated in this figure, the increase in hatching space would decrease the temperature. This is due to the fact that for a given geometry, the increase in hatching space would decrease the number of scans. Consequently, less heat is deposited to the control volume that causes the temperature to decrease. 


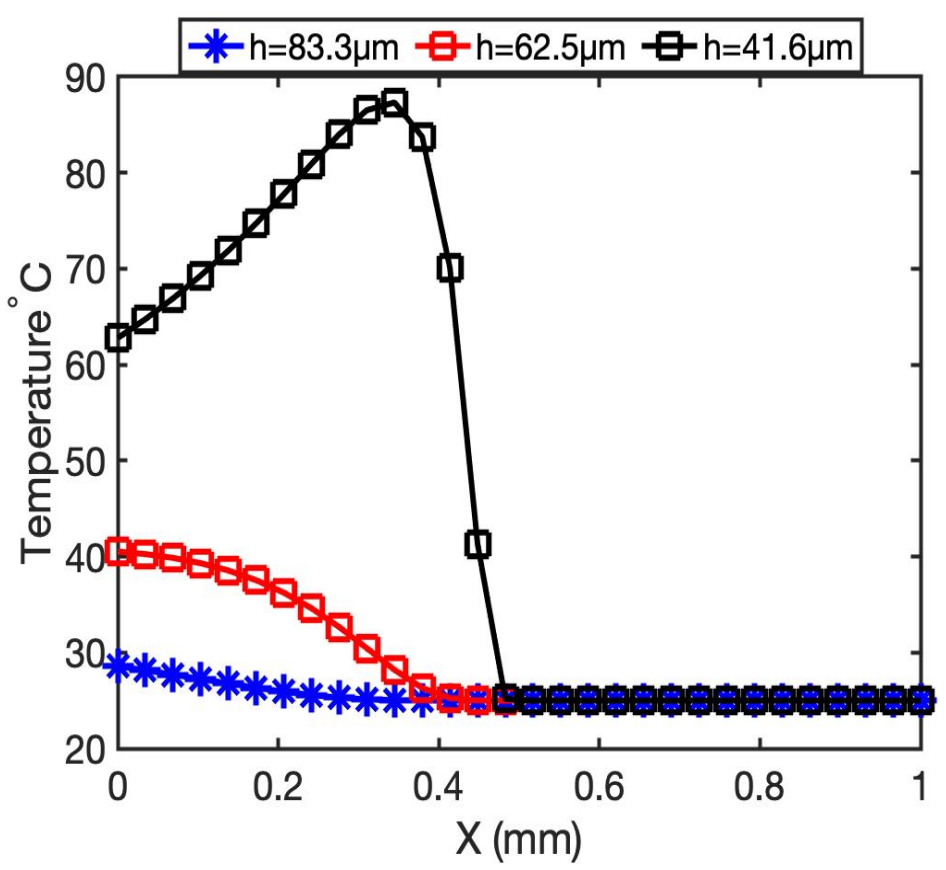

Figure 4. Evolution of temperature as a function of build part's length for various hatch spacings.

Due to the steep temperature gradient in metal AM, the thermal material properties vary significantly. Thus, considering temperature-sensitive thermal material properties is important in the modeling of the metal AM process. The thermal material properties of stainless steel grade 316L are listed in Table 1. Based on our observation, for the laser power of $50 \mathrm{~W}$ and a scan speed of $200 \mathrm{~mm} / \mathrm{s}$, the increase in hatching space, decreases the thermal conductivity, as shown in Figure 5 . For hatching space of $41.6 \mu \mathrm{m}$ the thermal conductivity starts at $17 \mathrm{~K} / \mathrm{m}^{\circ} \mathrm{C}$ and increases to $30 \mathrm{~K} / \mathrm{m}^{\circ} \mathrm{C}$ near the location of laser, and then it decreases gradually to $12 \mathrm{~K} / \mathrm{m}^{\circ} \mathrm{C}$. The decrease in thermal material properties is due to the fact that the powders are not affected by the laser yet and they are at room temperature. For the hatching space of $62.5 \mu \mathrm{m}$, the thermal conductivity is starts at $16.9 \mathrm{~K} / \mathrm{m}^{\circ} \mathrm{C}$ and the maximum thermal conductivity reaches to $22 \mathrm{~K} / \mathrm{m}^{\circ} \mathrm{C}$ near the location of the laser and then decreases to $12 \mathrm{~K} / \mathrm{m}^{\circ} \mathrm{C}$. For the hatching space of $83.3 \mu \mathrm{m}$, the thermal conductivity starts at $16.8 \mathrm{~K} / \mathrm{m}^{\circ} \mathrm{C}$ and reached the maximum value of $18 \mathrm{~K} / \mathrm{m}^{\circ} \mathrm{C}$ around the location of laser, and after the location of the laser, it gradually decreases to $12 \mathrm{~K} / \mathrm{m}^{\circ} \mathrm{C}$. It should be noted that the distance of the study line from the laser location has an influence on the magnitudes of the results, but the trend is always the same. To sum it up, since the thermal conductivity is a function of temperature, the decrease in temperature as caused by a larger hatching space would result in the reduction of thermal conductivity.

Table 1. Thermal material properties of 316L [18]. 

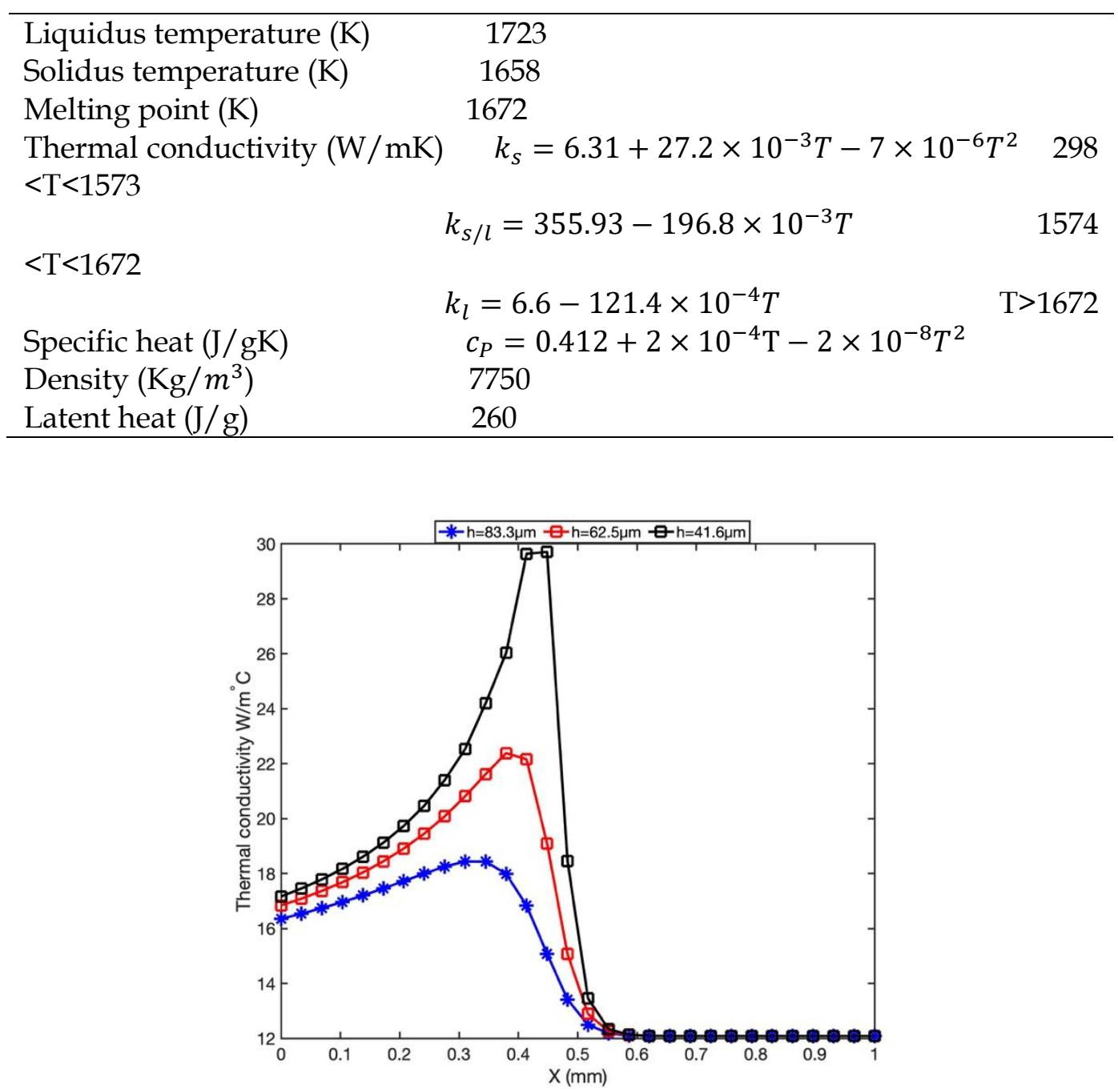

Figure 5. Evolution of thermal conductivity as a function of build part's length for various hatch spacings.

Due to the decrease in thermal conductivity as caused by a larger hatching space, the heat transfer rate decreases. The heat transfer rate is illustrated in Figure 6. As shown in this figure the absolute maximum heat transfer rate occurs near the location of the laser for different hatching spaces. The negative sign in the heat transfer plot implies that the direction of the heat transfer rate is the opposite of the assumed direction. It can be seen that the absolute heat transfer rate increases gradually up to the laser location. After the laser point, heat transfer gradually decreases to zero. The zero-heat transfer rate occurs at the regions where the powders are at room temperature and there is no temperature gradient. 


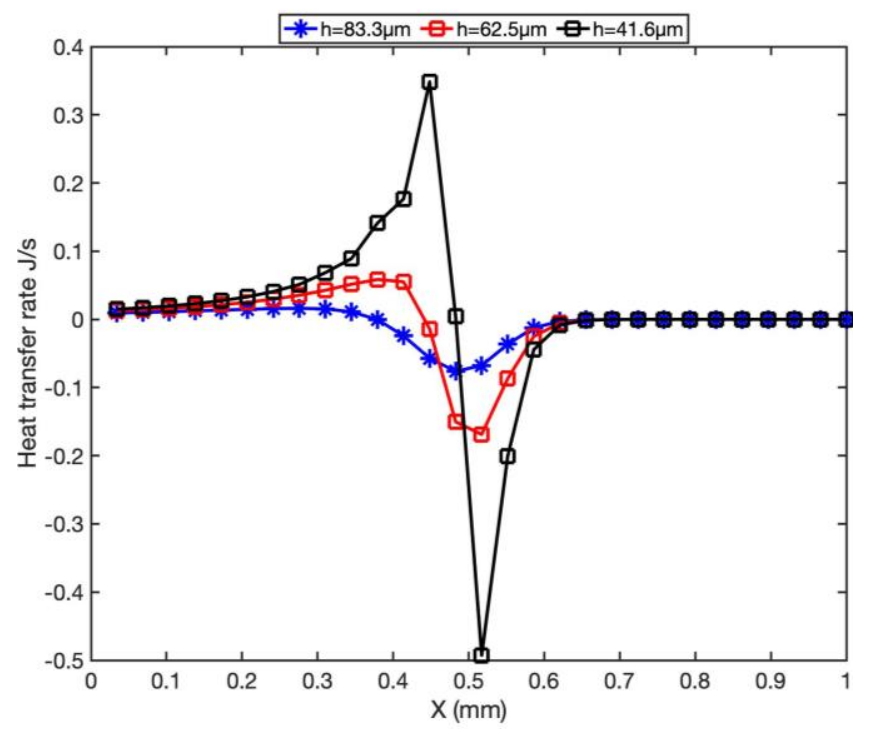

Figure 6. Evolution of heat transfer rate as a function of build part's length for various hatch spacings.

Considering temperature-sensitive thermal conductivity, a lower conductivity as caused by larger hatching space blocks the heat to flow away from the point of interest. Thus, the temperature at that point is kept higher, as shown in Figure 7. This would result in higher melt pool geometry as will discuss in the following sections.

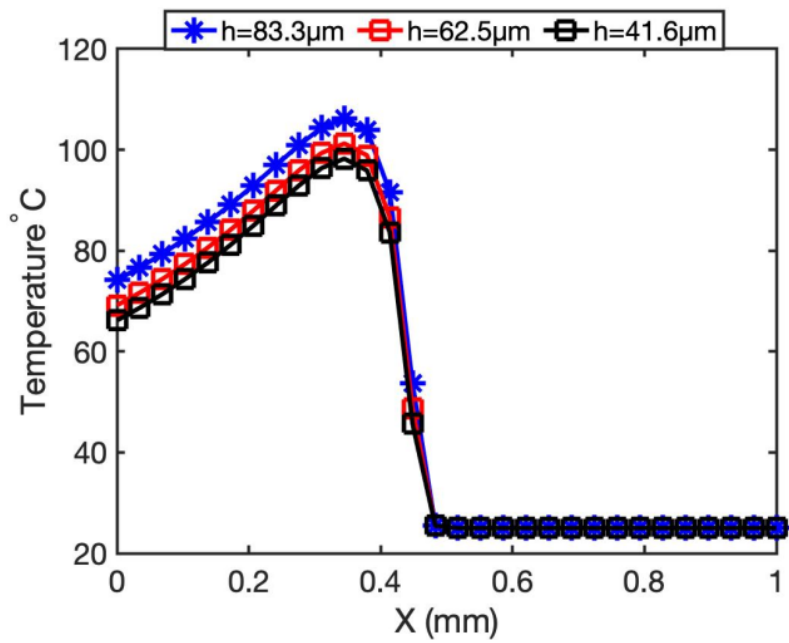

Figure 7. Evolution of surface temperature as a function of build part's length for various hatch spacings.

To sum it up, the hatching space effect on temperature has two competing effects;

1. Considering constant conductivity, a larger hatching space implies that less heat is deposited to the material due to the decrease in the number of scans.

2. Considering temperature-sensitive conductivity, a lower conductivity (as caused by a larger hatching space) blocks heat to flow away from a point of interest thus the temperature at that point is kept higher. Consequently, the melt pool geometry increases. 


\subsection{Effect of time spacing and hatching space on thermal material properties}

In this section, the effects of time spacing and hatching space on thermal material properties are investigated. Time spacing is the time delay between two irradiations and hatching space is the distance between two scans, as shown in Figure 1. In this work, the thermal material properties of S316L is considered to be temperature-dependent as listed in Table 1 [18]. It should be noted that the absorptivity is 0.8 and the scan strategy is unidirectional.

Figure 9(a) and (b) illustrate the effect of hatching space on thermal material properties in the scanning direction (x-direction). As shown in these figures, for a given laser power and scan speed which are $50 \mathrm{~W}$ and $200 \mathrm{~mm} / \mathrm{s}$, respectively, as the hatching space increases, the thermal conductivity, and specific heat decreases. The reason is that for a given geometry, the increase in hatching space would decrease the number of scans. Thus, less heat is deposited into the control volume which results in a reduction of temperature. Since the material properties are directly depended on temperature as listed in Table 1, the decrease in temperature induced by higher hatching space would result in a lower magnitude of the properties. Moreover, for a given hatching space, the thermal material properties increase gradually up to the laser location. It is worth noting that the maximum thermal properties do not occur at the location of the laser. This is because of the existence of the heat-affected zone which alters the behavior of the material due to the change of heat transfer rate. After the maximum point, the magnitude of the material properties diminishes since the laser has not affected the material yet. The laser location is at $\mathrm{X}=0.5$ $\mathrm{mm}$ for all the hatching spaces.

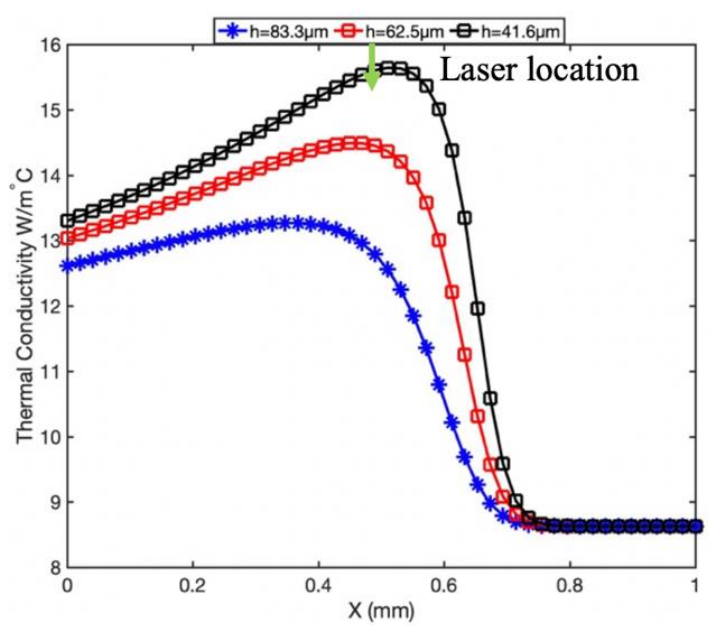

(a)

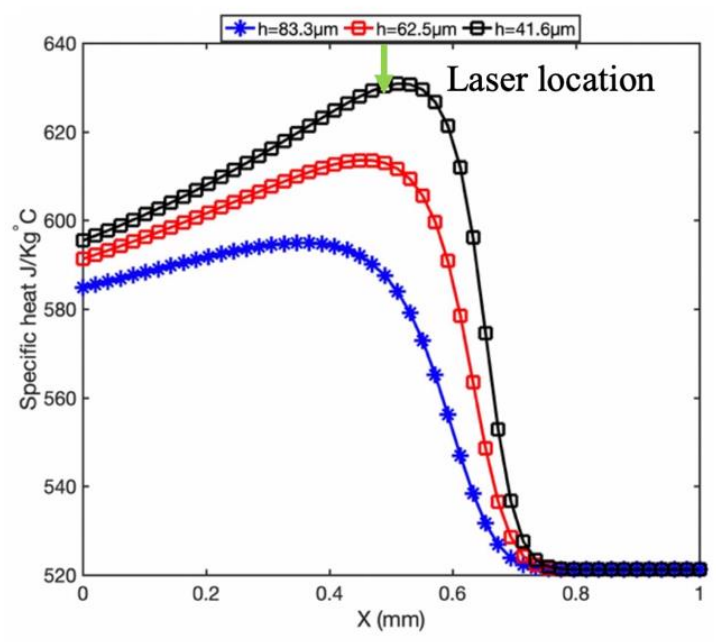

(b)

Figure 8. Effect of hatching space on (a) thermal conductivity (b) specific heat in the scan direction.

Figure 10(a) and (b) illustrate the effect of hatching space on thermal material properties in the transverse direction (y-direction). As shown in these plots, the same trend is observed for both the thermal conductivity and specific heat for different hatching spaces. For a given hatching space, the thermal material properties increase gradually. The maximum thermal conductivity and specific heat do not occur at the location of the laser. The higher the hatching space, the earlier 
the maximum point is achieved. The effect of the heat-affected zone of the previous irradiation on material properties could be the reason for this occurrence. After the maximum point, the thermal material properties decrease since the laser has not affected the powder yet. The location of the laser is at $0.25 \mathrm{~mm}$ in the $\mathrm{y}$-axis.

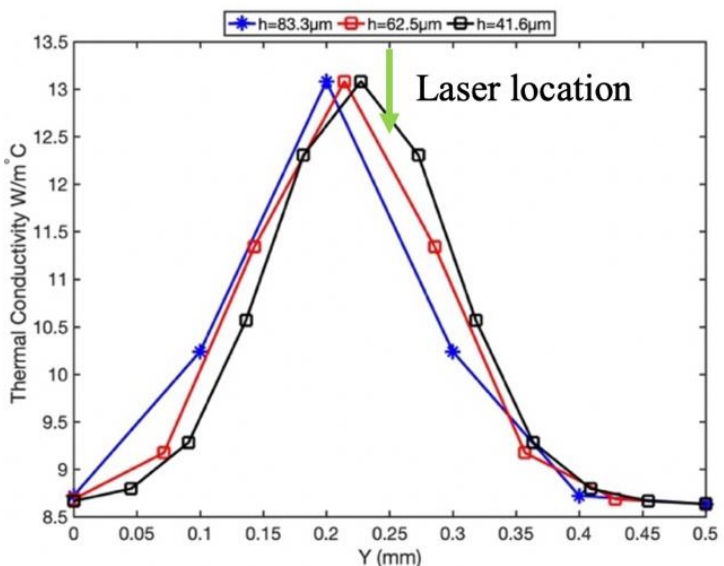

(a)

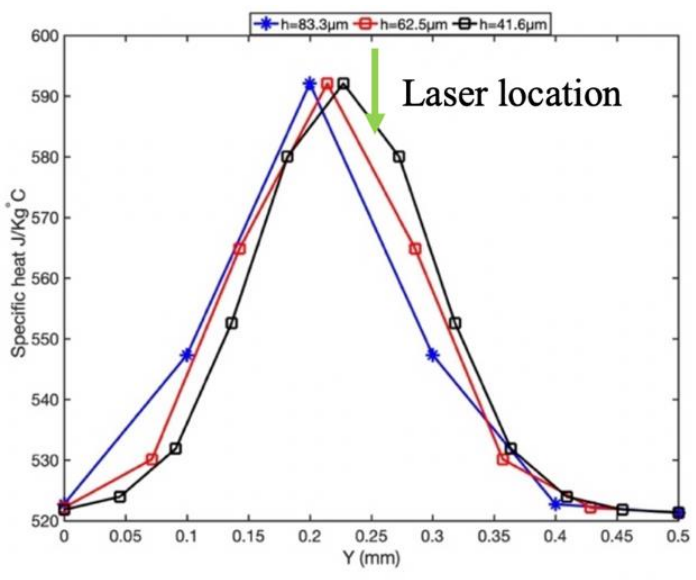

(b)

Figure 9. Effect of hatching space on (a) thermal conductivity (b) specific heat in the transverse direction.

Fig.11(a) and (b) illustrate the distribution of thermal properties in depth of the build part (zdirection). As shown in these figures, the hatching space does not have an influence on thermal properties in depth (z-direction).

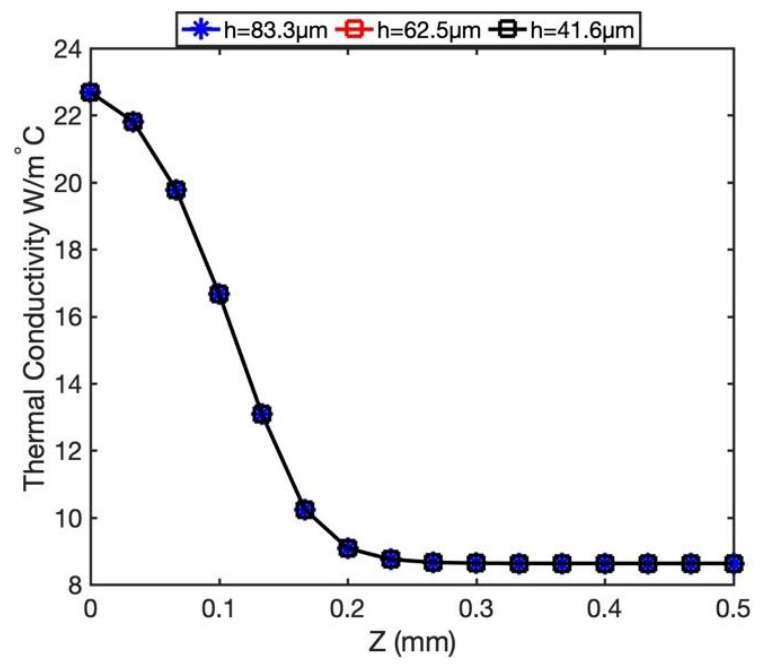

(a)

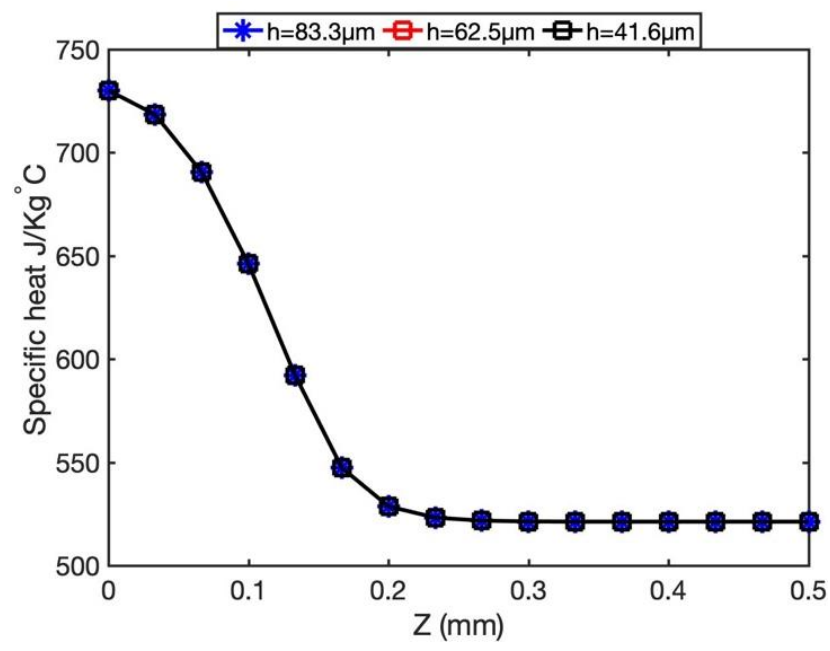

(b)

Figure 10. Effect of hatching space on (a) thermal conductivity (b) specific heat in the depth direction (z-direction).

The effect of time spacing on thermal material properties in the scanning direction is shown in Figure 12(a) and (b). Time spacing is the time delay between two irradiations. The laser power and scan speed are $50 \mathrm{~W}$ and $200 \mathrm{~mm} / \mathrm{s}$, respectively. The hatching space is $62.5 \mu \mathrm{m}$. As shown in these figures, the increase in time delay would decrease the properties. The maximum 
conductivity and specific heat do not occur at the location of the laser due to the existence of the heat-affected zone as explained previously.

The thermal material properties are the same for different timings in the transverse direction as shown in Figure 13. The thermal material properties have lower absolute values in the transverse direction compared to the scan direction. This means that the heat transfer mechanisms are different in each direction.

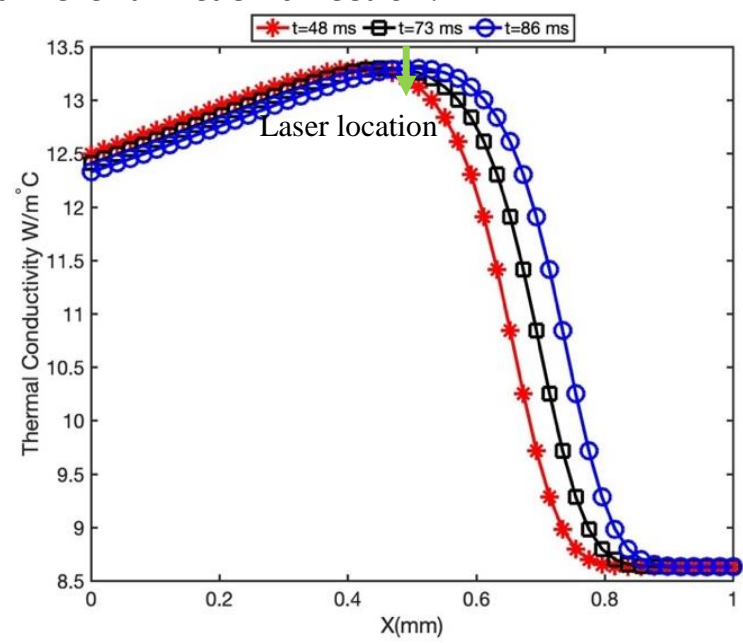

(a)

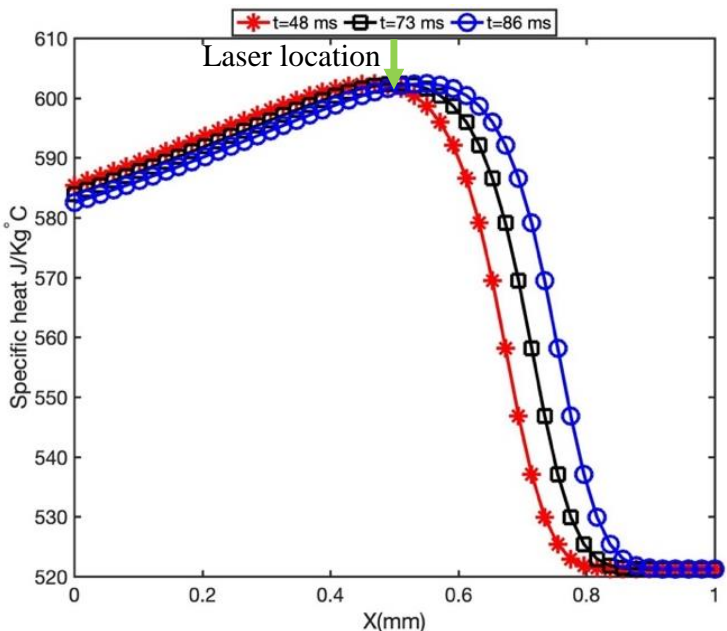

(b)

Figure 11. Effect of time spacing on (a) thermal conductivity (b) specific heat in the scan direction.

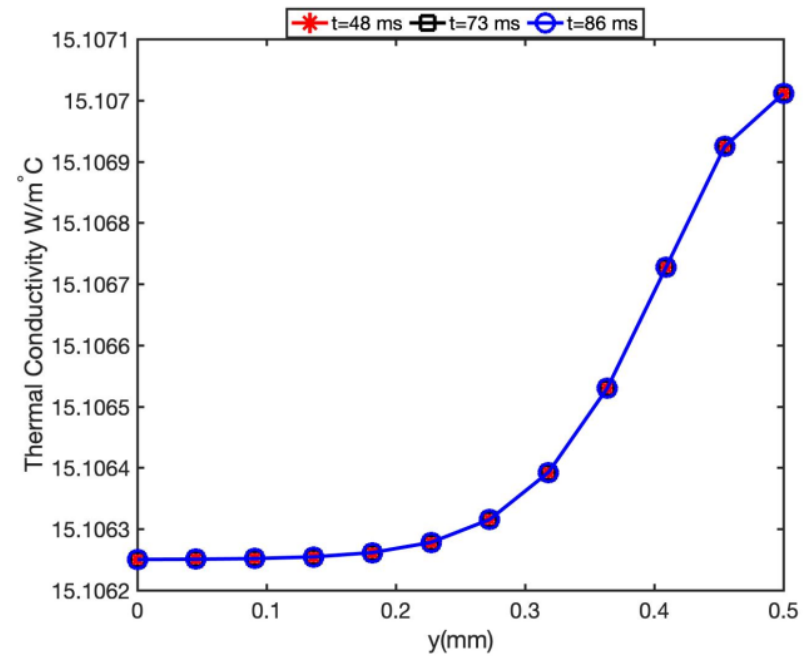

(a)

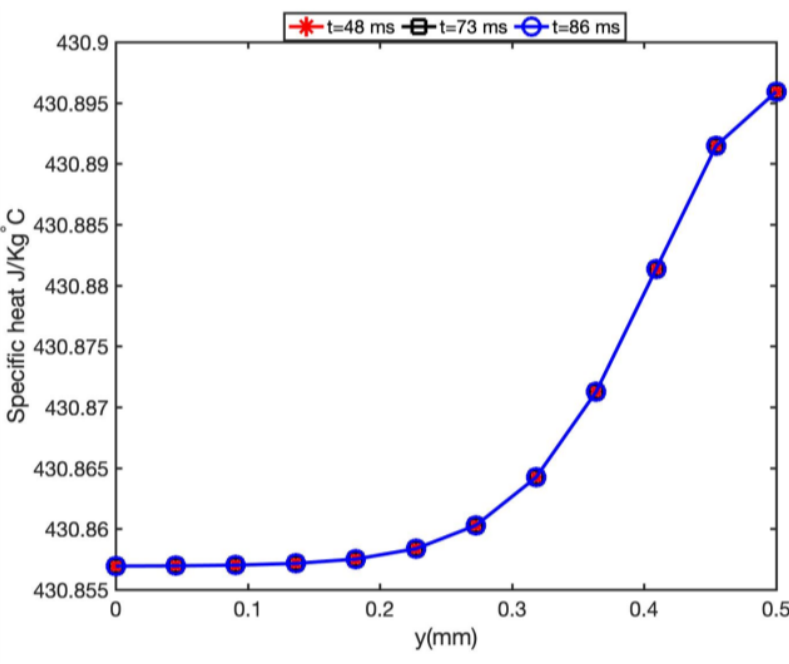

(b)

Figure 12. Effect of time spacing on (a) thermal conductivity (b) specific heat in the transverse direction.

\subsection{Effect of heat affected zone on melt pool geometry}

The moving point heat source approach is used to predict the temperature profile as explained in the Methodology section. The thermal material properties are temperature-dependent and the effect of heat-affected zone on thermal material properties are considered as explained in the 
previous section to predict the melt pool geometry. Figure 14 illustrates the melt pool geometry. The scan pattern is unidirectional in this work. In this section, our goal is to study the importance of considering the effect of heat affected zone on thermal material properties when modeling the temperature field.

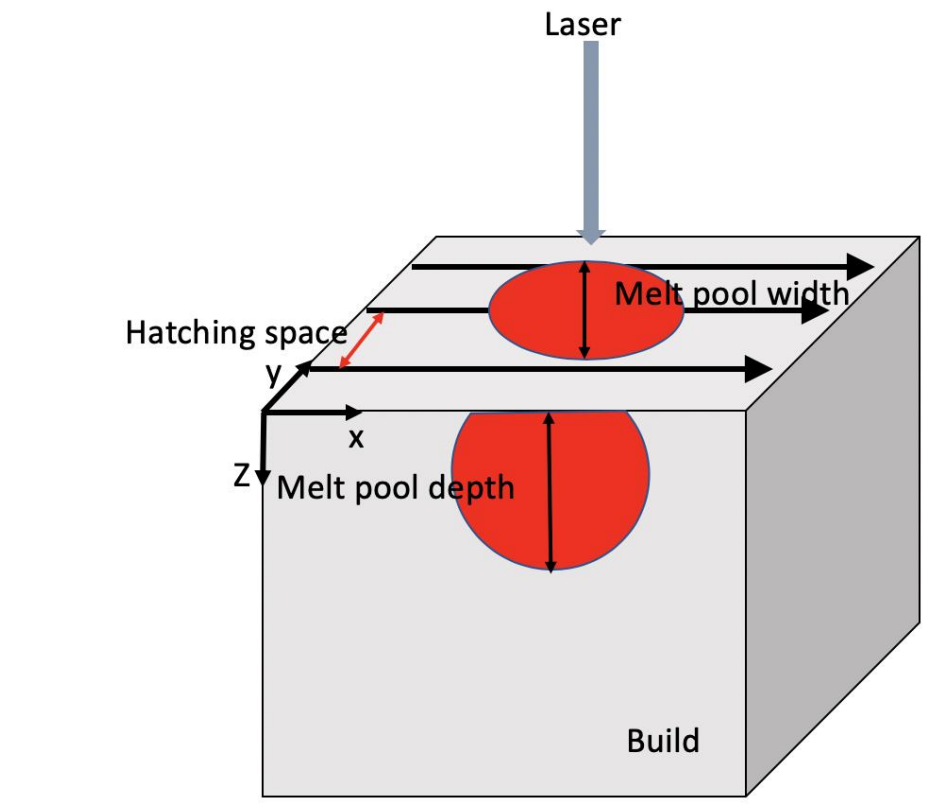

Figure 13. Illustration of the melt pool width, melt pool depth and hatching space.

To validate the proposed model, experimental values are used from the work of Yadroitsev [19]. The build parts' material is stainless steel grade 316L. The parts are made using selective laser melting (SLM) process. The laser power is fixed at $50 \mathrm{~W}$, and scan speed varies from $200 \mathrm{~mm} / \mathrm{s}$ to $280 \mathrm{~mm} / \mathrm{s}$. SLM experiments are carried out using single-mode continuous-wave Ytterbium fiber laser operating at $1075 \mathrm{~nm}$ wavelength. The laser beam has the Gaussian profile with a spot size of $70 \mu \mathrm{m}$. The powder layer thickness is $80 \mu \mathrm{m}$. The melt pool geometry is captured using a thermal camera.

Figure 15 (a) to (f) illustrate the melt pool geometry without considering the effect of the heataffected zone on thermal material properties and melt pool geometry. It is worth mentioning that the melting point of $\mathrm{S} 316 \mathrm{~L}$ is $1400^{\circ} \mathrm{C}$. 


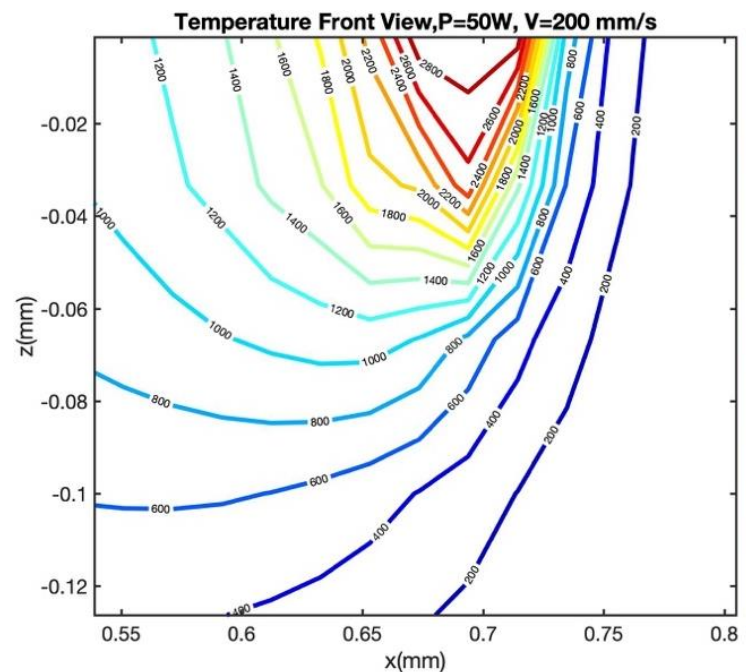

(a)

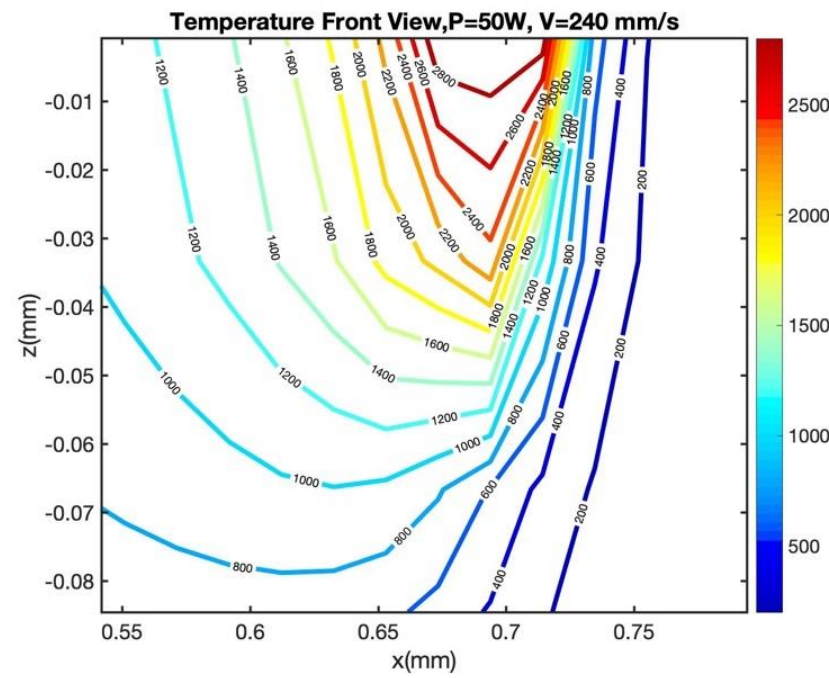

$(\mathrm{c}))$ wow, $\mathrm{V}=280 \mathrm{~mm} / \mathrm{s}$

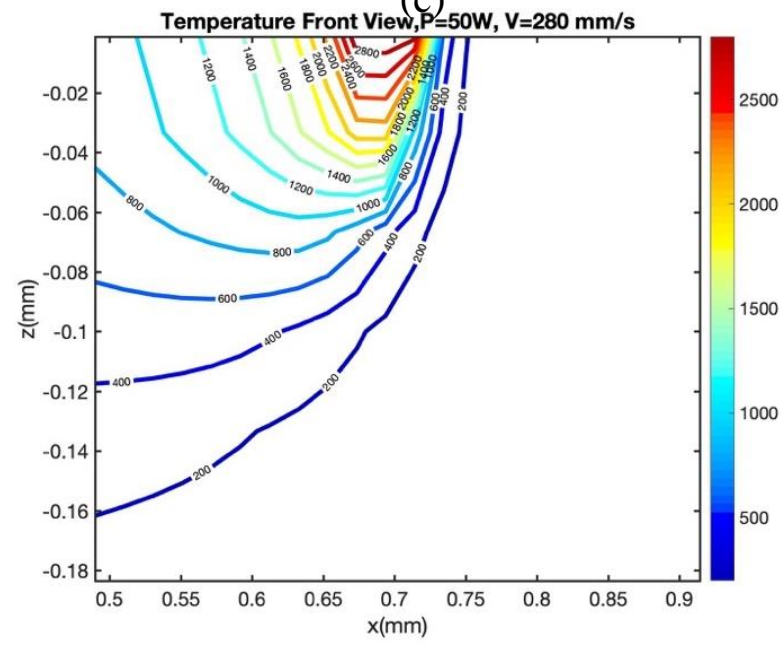

(e)

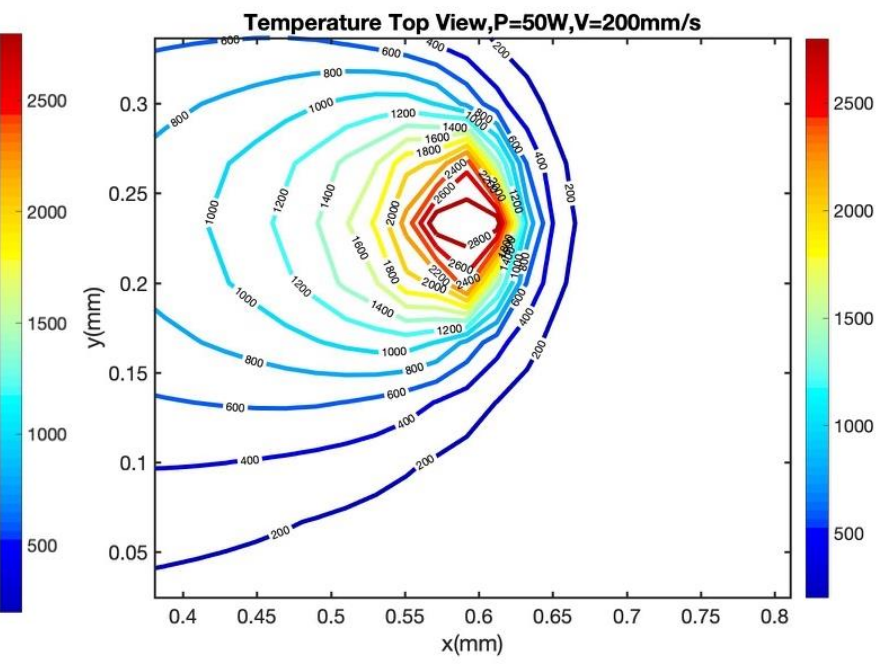

(b)

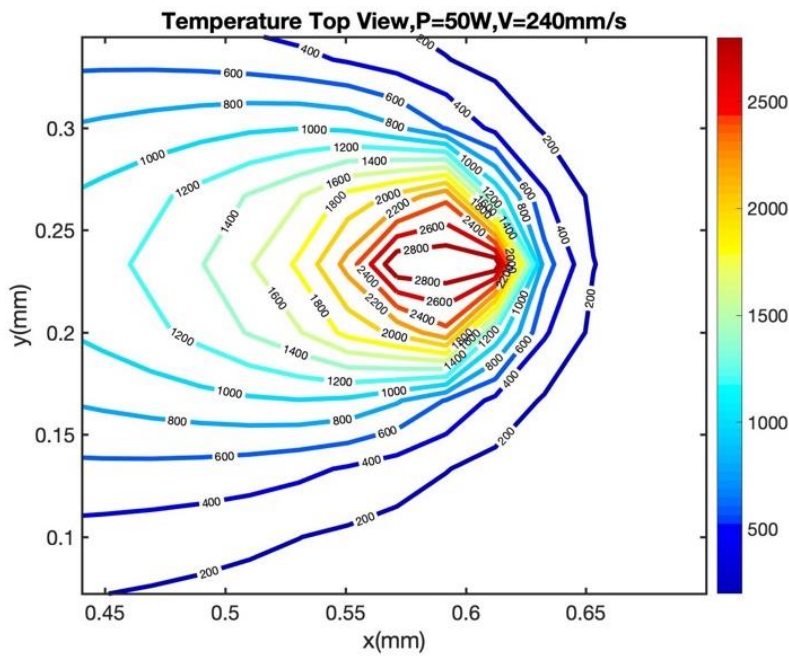

(d)

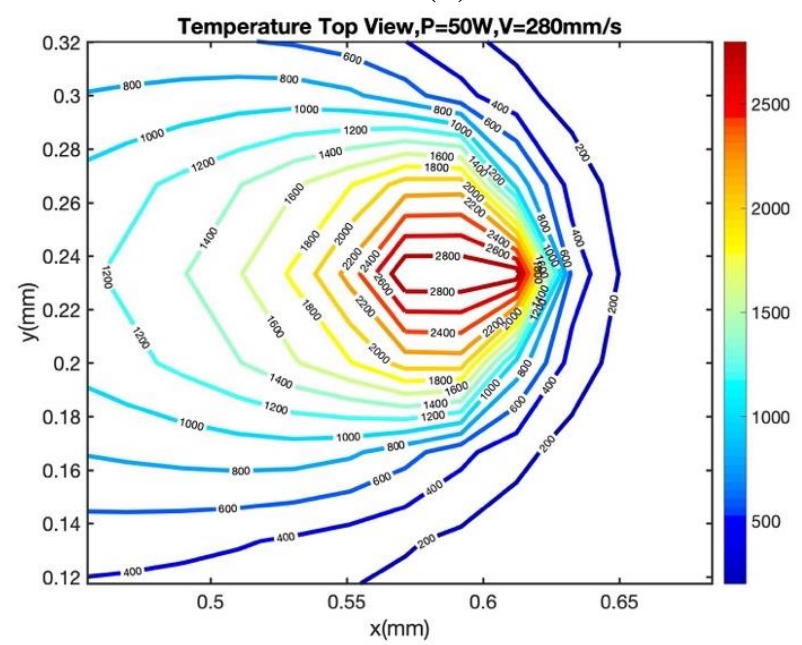

(f)

Figure 14. Predicted melt pool geometry without considering effect of heat affected zone on thermal material properties for a fix laser power of $50 W$, and scan speed of $(a, b) V=200 \mathrm{~mm} / \mathrm{s},(c, d) V=240 \mathrm{~mm} / \mathrm{s},(e, f) V=280 \mathrm{~mm} / \mathrm{s}$ 
Figure 16 (a) to (f) illustrate the melt pool geometry considering the effect of heat affected zone on melt pool geometry.

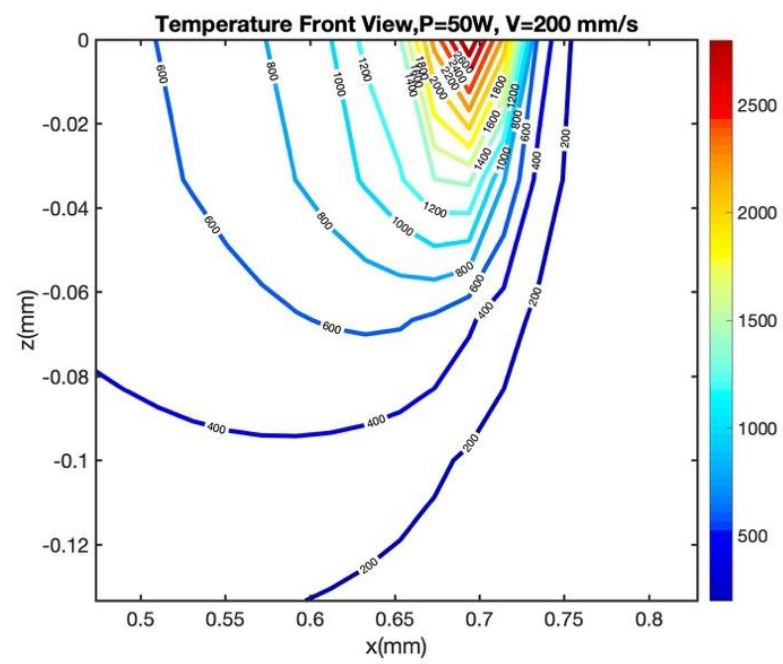

(a)

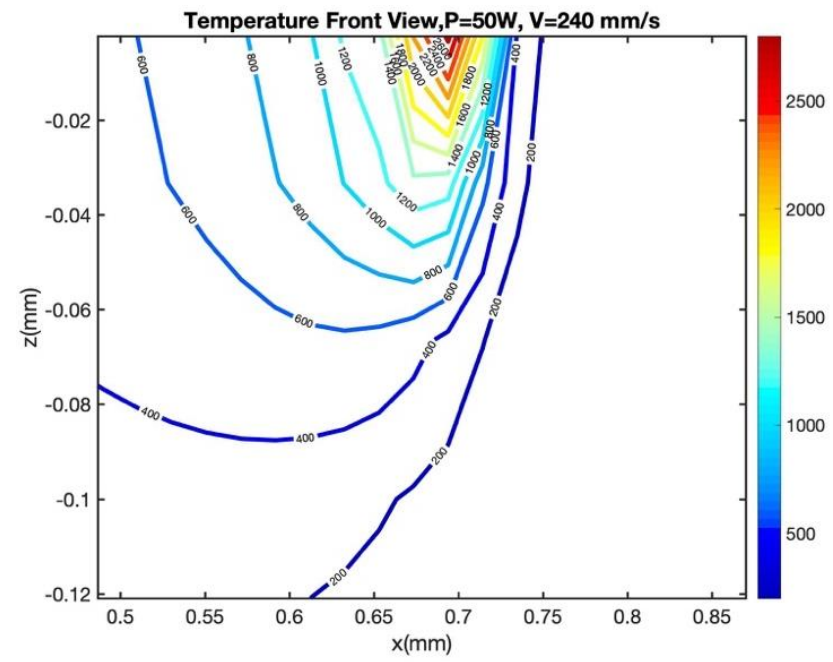

(c)

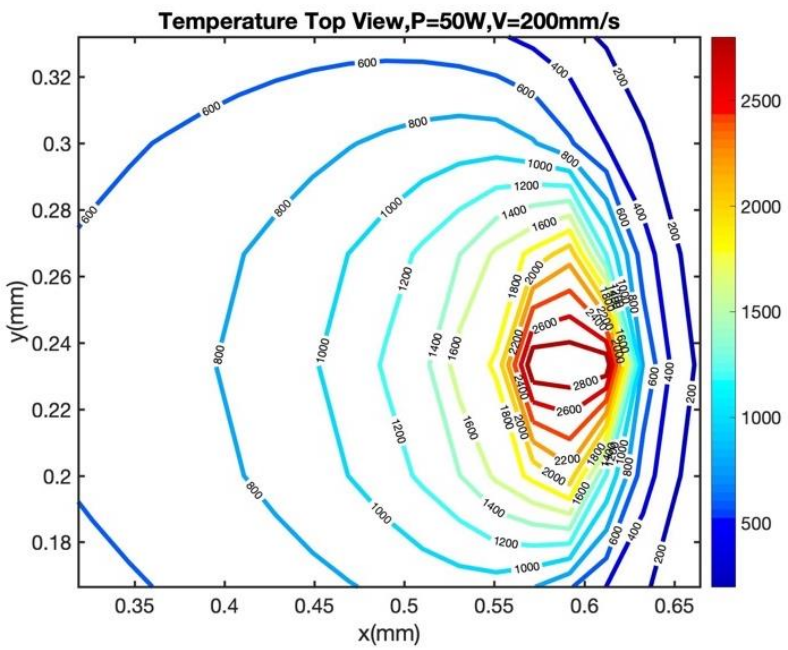

(b)

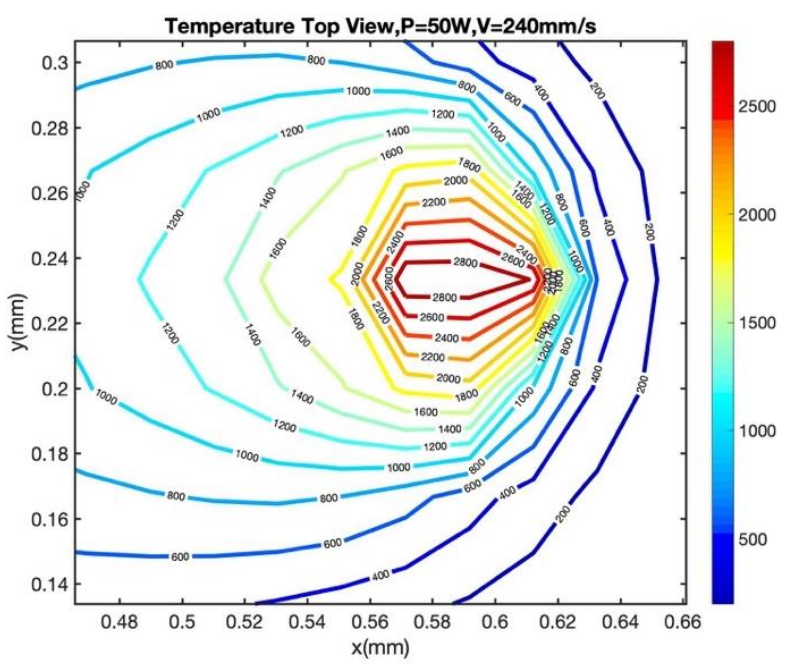

(d) 


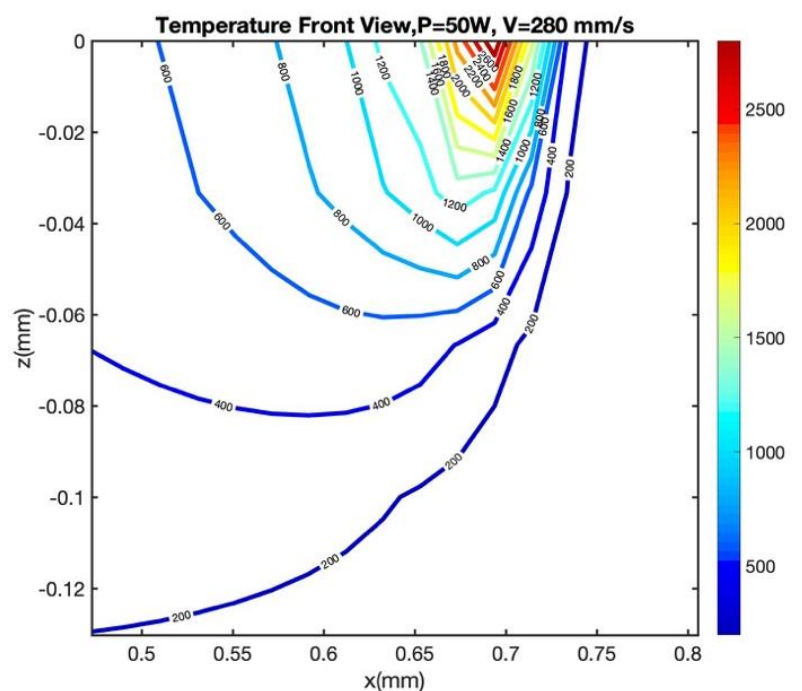

(e)

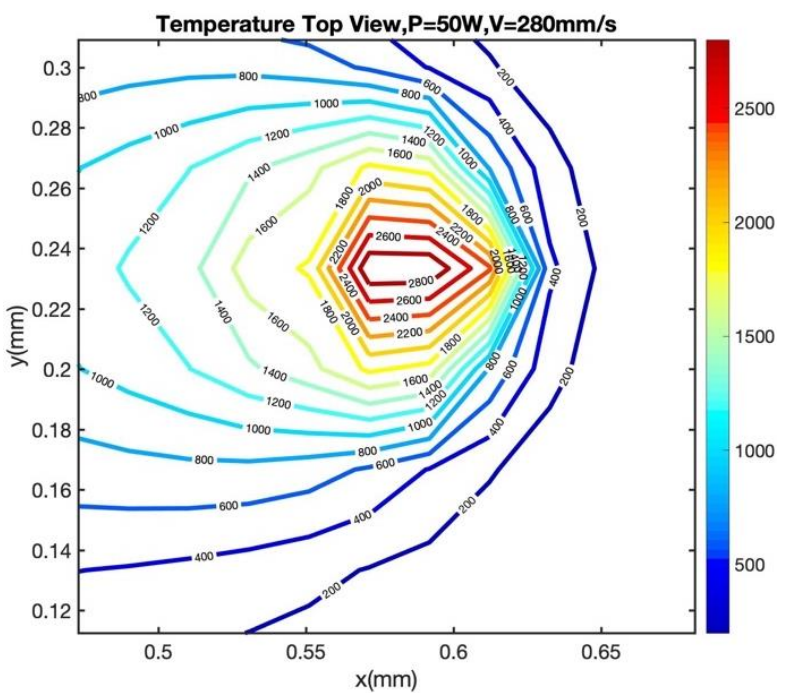

(f)

Figure 15. Predicted melt pool geometry with considering effect of heat affected zone on thermal material properties for a fix laser power of $50 \mathrm{~W}$, and scan speed of $(a, b) V=200 \mathrm{~mm} / \mathrm{s},(c, d) V=240 \mathrm{~mm} / \mathrm{s},(e, f) V=280 \mathrm{~mm} / \mathrm{s}$

Figure 17 (a) and (b) is a comparison of the predicted melt pool size with experimental values. The blue bar is the predicted melt pool size without considering the effect of heat affected zone on material properties, the yellow bar is the predicted melt pool size with considering the effect of heat affected zone on material properties, and the error bar shows the experimental values. As shown in these figures, the melt pool width and depth are overestimated when the effect of heataffected zone is ignored (blue bar). According to these figures, the melt pool width and depth show close consistency with experimental reports when the effect of heat affected zone is considered in the modeling (yellow bar).

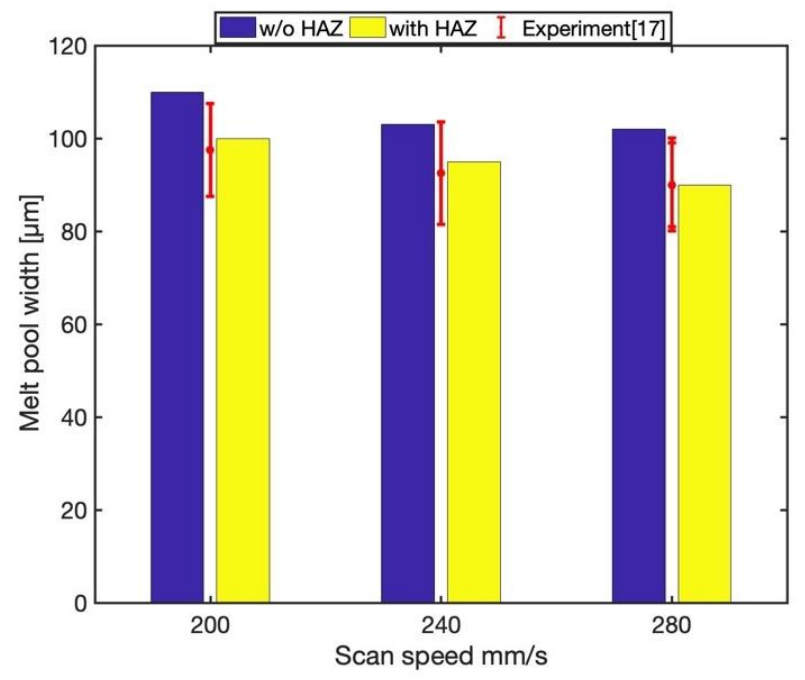

(a)

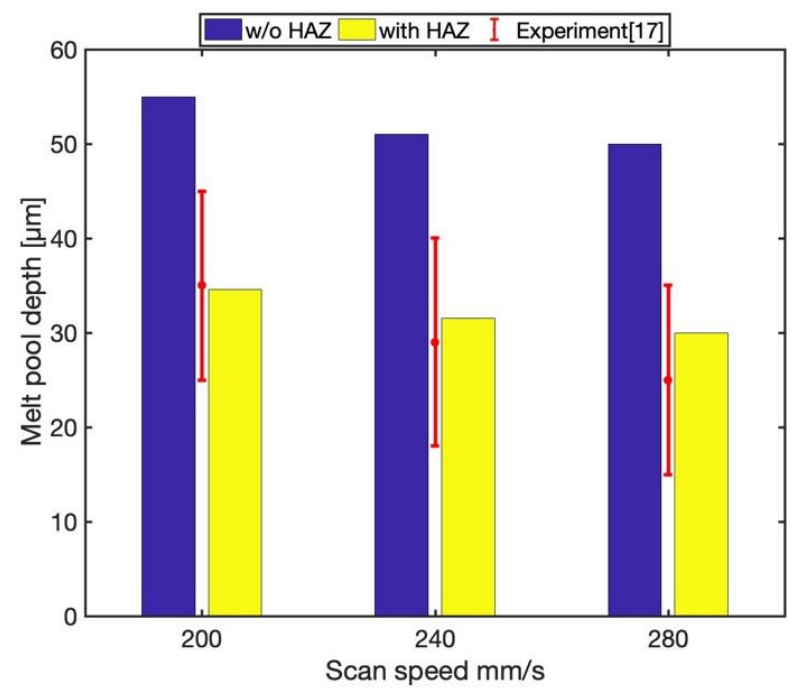

(b)

Figure 16. Comparison of the predicted melt pool (a)width and (b) depth without considering the effect of heat affected zone (HAZ) (blue bar), with considering the effect of heat affected zone (HAZ) (yellow bar), and experimental values (red error bar) with the fixed laser power of $50 \mathrm{~W}$. 


\subsection{Effect of hatching space on melt pool geometry}

The hatching space is another important parameter along with laser power and scan speed associated with the SLM process. Figure 14 illustrates how the build part forms with unidirectional laser tracks. To have a better part quality, the condition should be set in such a way that there will be an overlap between two hatches. Considering the overlap in the SLM process is necessary since the continuity between tracks lead to a solid sample.

Figure 18 depicts the effect of hatching space on melt pool geometry. As explained before, the increases in hatching space decrease the thermal conductivity. As a result of the reduction in thermal conductivity induced by higher hatching space, less heat conducted through the solid and most of the heat concentrates at the location of the laser and causes the melt pool width to increase. As explained in section 3.1, the hatching space effect on temperature has two competing aspects; 1) Considering constant conductivity, a larger hatching space implies that less heat is deposited to the material due to the decrease in the number of scans. 2)Considering temperaturesensitive conductivity, a lower conductivity (as caused by a larger hatching space) blocks heat to flow away from a point of interest thus the temperature at that point is kept higher. Thus, the melt pool geometry increases.

According to our observation, the melt pool depth is not affected by the hatching space, and it is more dependent on the laser power and scan speed. The thermal properties are governing the heat transfer rate. Thus, as explained in the previous section, the hatching space does not have an influence on material properties in depth (z-direction) as shown in Figure 11(a) and (b). Consequently, since the material has the same behavior in depth (z-direction) under different hatching spaces, the melt pool depth is not affected by hatching space, as well.

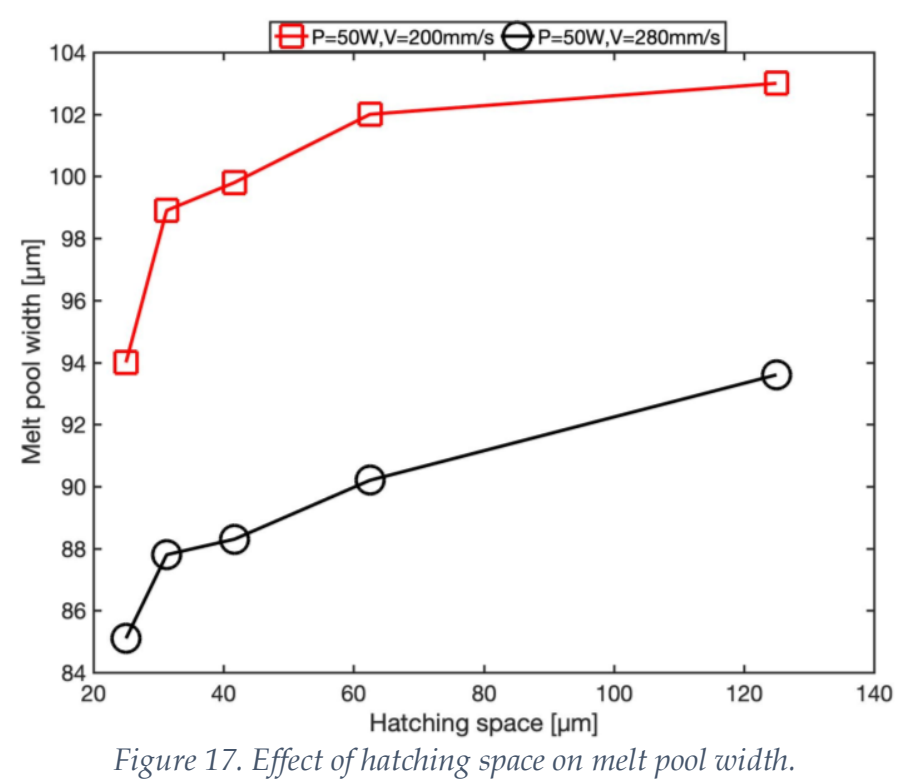

\section{Summary and Conclusions}


Theoretical accounts mostly consider the roles of laser power and scan speed on the formation of the temperature field. However, other scan strategy parameters such as time delay between two irradiations and hatching space have a significant effect on the heat transfer mechanisms in metal additive manufacturing processes. This work provides a novel approach to predict the temperature field during the SLM process. A physics-based analytical model is utilized to predict the 3D temperature profile using the moving heat source approach. In this modeling, due to the steep temperature gradient during the AM process, the material properties vary significantly. Consequently, the material properties are considered to be temperature-dependent. Also, due to the repeated heating and cooling, the build part undergoes several melting and solidification cycles. This physical process is considered by modifying the specific heat using the latent heat of fusion. Moreover, the interaction of successive layers has an impact on heat transfer mechanisms. Thus, the multilayer aspect of the SLM process is considered by incorporating the temperature history from previous layers. Furthermore, the effect of heat affected zone on thermal material properties is considered using the superposition of material properties in regions where the temperature field of two consecutive irradiations have overlap.

In this study, the effects of temperature-sensitive material properties and constant material properties on the temperature field are investigated separately. Moreover, the behavior of the thermal material properties under different scan strategies is studied. Furthermore, the importance of considering the effect of heat affected zone on thermal material is studied through the prediction of melt pool geometry. Finally, the effect of hatching space on melt pool geometry is investigated.

It is shown that the hatching space has two competing effects on the temperature field. 1) Considering constant conductivity, a larger hatching space implies that less heat is deposited to the material due to the decrease in the number of scans. 2) Considering temperature-sensitive conductivity, a lower conductivity (as caused by a larger hatching space) blocks heat to flow away from a point of interest thus the temperature at that point is kept higher. Consequently, the melt pool geometry increases.

Moreover, for the temperature-dependent thermal material properties, as the hatching space increases, the thermal conductivity, and specific heat decrease. This is because, for a given geometry, the increase in hatching space would decrease the number of scans. Thus, less heat is deposited into the control volume. As a result, since the material properties have a direct relationship with temperature, the decrease in temperature would decrease the properties.

Furthermore, for the temperature-dependent thermal material properties, as the time delay between two irradiation increases, the thermal conductivity, and specific heat decrease.

Also, it is shown that considering the effect of heat affected zone on material properties would result in a more accurate prediction of temperature field and better agreement is achieved with experimental results.

Last, it is shown that the increase in hatching space would result in a bigger melt pool width. This is because the lower thermal conductivity as caused by a larger hatching space block the heat to flow away from the point of interest thus the temperature at that point is kept higher. This would result in higher melt pool geometry.

\section{Declarations of interest: none}

Acknowledgements: The funding is confidential

Author Contributions: Conceptualization, Elham Mirkoohi; Data curation, Elham Mirkoohi; Formal analysis, Elham Mirkoohi; Investigation, Elham Mirkoohi; Resources, Daniel E. Sievers 
and Hamid Garmestani; Supervision, Steven Y. Liang; Validation, Elham Mirkoohi; Visualization, Elham Mirkoohi; Writing - original draft, Elham Mirkoohi; Writing - review \& editing, Steven Y. Liang.

\section{Reference}

1. Zhang, L., et al., Manufacture by selective laser melting and mechanical behavior of a biomedical Ti-24Nb-4Zr-8Sn alloy. Scripta Materialia, 2011. 65(1): p. 21-24.

2. Mukherjee, T., W. Zhang, and T. DebRoy, An improved prediction of residual stresses and distortion in additive manufacturing. Computational Materials Science, 2017. 126: p. 360372.

3. Cheng, B., et al., On process temperature in powder-bed electron beam additive manufacturing: model development and validation. Journal of Manufacturing Science and Engineering, 2014. 136(6): p. 061018.

4. Lee, Y. and D.F. Farson, Simulation of transport phenomena and melt pool shape for multiple layer additive manufacturing. Journal of Laser Applications, 2016. 28(1): p. 012006.

5. Michaleris, P., Modeling metal deposition in heat transfer analyses of additive manufacturing processes. Finite Elements in Analysis and Design, 2014. 86: p. 51-60.

6. Mirkoohi, E., et al., Thermal modeling of temperature distribution in metal additive manufacturing considering effects of build layers, latent heat, and temperature-sensitivity of material properties. Journal of Manufacturing and Materials Processing, 2018. 2(3): p. 63.

7. Mirkoohi, E., et al., Heat Source Modeling in Selective Laser Melting. Materials, 2019. 12(13): p. 2052.

8. Ribeiro, S., et al., HEAT CONDUCTION IN MOVING SOLIDS USING GREEN'S FUNCTION. RETERM-Thermal Engineering, 2018. 14(1): p. 65-70.

9. Craeghs, T., et al., Determination of geometrical factors in Layerwise Laser Melting using optical process monitoring. Optics and Lasers in Engineering, 2011. 49(12): p. 1440-1446.

10. Krauss, H., C. Eschey, and M. Zaeh. Thermography for monitoring the selective laser melting process. in Proceedings of the Solid Freeform Fabrication Symposium. 2012.

11. Price, S., et al. Experimental temperature analysis of powder-based electron beam additive manufacturing. in Proceedings of the Solid Freeform Fabrication Symposium. 2013.

12. Mirkoohi, E. and R. Malhotra. Effect of Particle Shape on Neck Growth and Shrinkage of Nanoparticles. in ASME 2017 12th International Manufacturing Science and Engineering Conference collocated with the JSME/ASME 2017 6th International Conference on Materials and Processing. 2017. American Society of Mechanical Engineers.

13. Mirkoohi, E., P. Bocchini, and S.Y. Liang, An analytical modeling for process parameter planning in the machining of Ti-6Al-4V for force specifications using an inverse analysis. The International Journal of Advanced Manufacturing Technology, 2018. 98(9-12): p. 2347-2355.

14. Mirkoohi, E., P. Bocchini, and S.Y. Liang, Analytical temperature predictive modeling and non-linear optimization in machining. The International Journal of Advanced Manufacturing Technology, 2019: p. 1-10.

15. Mirkoohi, E., P. Bocchini, and S.Y. Liang, Inverse analysis of residual stress in orthogonal cutting. Journal of Manufacturing Processes, 2019. 38: p. 462-471. 
16. Tabei, A., et al., Modeling of texture development in additive manufacturing of Ni-based superalloys. The International Journal of Advanced Manufacturing Technology, 2019.

17. Ji, X., et al., Analytical modeling of post-printing grain size in metal additive manufacturing. Optics and Lasers in Engineering, 2020. 124: p. 105805.

18. Valencia, J.J. and P. Quested, Thermophysical properties. Modeling for Casting and Solidification Processing, 2001. 189.

19. Yadroitsev, I., et al., Energy input effect on morphology and microstructure of selective laser melting single track from metallic powder. Journal of Materials Processing Technology, 2013. 213(4): p. 606-613. 